\title{
Metabolic syndrome and heart failure: data from the FADOI CONFINE study
}

Paolo Biagi, ${ }^{1}$ Roberto Nardi, ${ }^{2}$ Giovanni Mathieu, ${ }^{3}$ Giorgio Vescovo, ${ }^{4}$ Giuseppe Scanelli ${ }^{5}$ on behalf of the CONFINE Study Group

${ }^{1}$ Internal Medicine, Valdichiana Hospital, Montepulciano (SI); ${ }^{2}$ Internal Medicine C, Maggiore Hospital, Bologna; ${ }^{3}$ Internal Medicine, Agnelli Hospital, Pinerolo (TO); ${ }^{4}$ Internal Medicine, S. Bortolo Hospital, Vicenza; ${ }^{5}$ Internal Medicine, S. Anna

Hospital, Ferrara, Italy

\begin{abstract}
Approximately 20\%-30\% of the population in industrialized countries suffers from metabolic syndrome (MetS), a condition that may double the risk of diabetes mellitus and heart diseases in the normal population. Both MetS per se and its components increase the risk of atherosclerosis and acute coronary artery disease and heart failure (HF). We reviewed the data from a recent survey of patients admitted to Italian internal medicine wards due to chronic heart failure to ascertain the prevalence and the relationships between MetS and HF in real life patients. Our data shows that some risk factors for this syndrome (above all obesity) reflect a sort of Janus phenomenon in that they are well-recognized risk factors for HF in young people, but they lose their unfavorable predictive value in elderly patients with HF.
\end{abstract}

\section{Introduction}

Metabolic syndrome (MetS) describes the clustering of various metabolic components, including dysglycemia (glucose intolerance/diabetes mellitus), hypertension, elevated triglyceride levels, low highdensity lipoprotein cholesterol levels and obesity. ${ }^{1,2}$

A close relationship has been repeatedly demonstrated between the individual components of MetS and/or MetS as a whole and an increased risk of atherosclerotic diseases. A poor outcome has also been described after acute coronary syndrome ${ }^{3}$ and, more recently, in MetS with congestive heart failure. ${ }^{4-8}$ However the prevalence and clinical significance of MetS in chronic heart failure (CHF) still remain to be fully elucidated.

Correspondence: Paolo Biagi, Hospital of Montepulciano, 53045 Siena, Italy.

Tel.: +39.340.6293252 - Fax: +39.0578.716422.

E-mail:paolobiagi48@libero.it

Key words: metabolic syndrome, heart failure.

Received for publication: 5 July 2013.

Revision received: 11 September 2013.

Accepted for publication: 12 September 2013.

This work is licensed under a Creative Commons Attribution NonCommercial 3.0 License (CC BY-NC 3.0).

CCopyright P. Biagi et al., 2014

Licensee PAGEPress, Italy

Italian Journal of Medicine 2014; 8:169-175

doi:10.4081/itjm.2014.406
The aging of the population, the decreased mortality from coronary heart disease over the past few decades, the growing number of treatment options for $\mathrm{HF}$ and its comorbidities have led to an increased prevalence of heart failure (HF) with quite different characteristics compared with those of the patients randomized for the clinical trials. ${ }^{9-11}$ Then we have investigated the relationship between MetS and HF reported in the CONFINE (Comorbidities and Outcome iN patients with chronic heart Failure: a study in INternal $\mathrm{mEdicine}$ units) $\mathrm{study}^{12}$ to define its prevalence and clinical significance in real world patients.

\section{Materials and Methods}

The CONFINE study is a multi-centric longitudinal observational study, performed according to the spot analysis method. It was conducted in 91 internal medicine units evenly distributed throughout Italy, which enrolled a total of 1411 patients with HF present in the wards in 5 well-defined days (index days) in 2006-2007 according to the European Society of Cardiology (ESC) 2005 guidelines without any exclusion criteria. ${ }^{13}$

The patients were divided into 2 groups, with MetS or without MetS (No-MetS), according to the most widely accepted definition from the Adult Treatment Panel III (ATP III) of the National Cholesterol Education Program (NCEP) (Table 1). ${ }^{14}$

Baseline demographic data (age, sex, height, body weight, and waist), CHF New York Heart Association (NYHA) class and etiology, blood pressure, pulse rate, laboratory parameters, medications, including angiotensin-converting enzyme inhibitors (ACEI), an- 
giotensin-receptor blockers (ARB), $\beta$-blockers were collected from the medical records. The left ventricular ejection fraction (LVEF) was measured by echocardiography.

The following comorbidities were evaluated: i) chronic renal failure, stratified by creatinine clearance calculated according to Cockroft Gould; ii) previously diagnosed diabetes mellitus, specific therapy or blood glucose levels above $126 \mathrm{mg} / \mathrm{dL}$; iii) hypertension with stages of severity, according to the European Society of Hypertension (ESH)-ESC guidelines, ${ }^{15}$ previously diagnosed chronic obstructive pulmonary disease or specific therapy; iv) chronic inflammatory diseases (rheumatoid arthritis, ulcerative colitis, Crohn's disease, etc.); v) dementia evaluated on the basis of the Pfeiffer test; ${ }^{16}$ vi) anemia defined according to World Health Organization (WHO) criteria; ${ }^{17}$ vii) cerebrovascular disease according to a history of stroke or transient ischemic attack; viii) disability tested according to the Barthel index score. ${ }^{18}$

In adults, overweight was defined as a body mass index (BMI) of 25 to $29.9 \mathrm{~kg} / \mathrm{m}^{2}$, and obesity was defined as a BMI of $30 \mathrm{~kg} / \mathrm{m}^{2}$ or higher.

\section{Statistical analysis}

Data was stratified according to MetS status. The prevalence of MetS was determined by dividing the number of patients positive for MetS $(\geq 3$ of the NCEP-ATP III criteria) by the total number of patients in the CONFINE study. Continuous variables are expressed as mean $\pm \mathrm{SEM}$ (standard error mean). Comparisons between 2 groups with and without Mets were performed with unpaired T-test for continuous variables and $\mathrm{X}$-test for categorical variables.

$\mathrm{P}<0.05$ was considered to be statistically significant.

\section{Results}

In the CONFINE study, 515 subjects met the NCEP III criteria of MetS (284 F), mean age was a lit- tle younger than No-MetS (F 80.12 7.9 and $\mathrm{M}$ $75.08 \pm 9.4$ ) (Table 1), less than $5 \%$ of patients fulfilled the five inclusion criteria.

The characteristics of MetS and No-MetS subjects are reported in Table 2 .

The characteristics by gender of MetS and NoMetS subjects are reported in Table 3. Females are older than males in both groups (79.9 \pm 7.6 vs $75.1 \pm 8.8$ for Mets patients, $\mathrm{P}<0.001$, and $81.2 \pm 9.2$ vs $77.4 \pm 10.5$ in No-Mets patients).

Systolic function (LVEF) is similar in both sexes, but in women LVEF $>50 \%$ is prevalent $(61.4 \% v s$ 38.6; P: not significant).

The therapy administered on admission is summarized in Table 4.

It should be noticed that the prevalence of ARBs and $\beta$ blockers and, marginally, of ACEI, diuretics and Ca-channel blockers differ between the two groups, given the higher prevalence of hypertension in the MetS subgroup.

\section{Comorbidities}

Comorbidities were evaluated in the two groups. Some differ by gender and some are part of the inclusion criteria for MetS. Values on admission and at discharge are reported in Table 5.

Subjects with no cognitive defects were more numerous in the MetS group, moderate to severe dementia was significantly higher in males and females of the No-MetS group on admission $(5.5 \%$ vs $4.2 \%$; $\mathrm{P}<0.05$ and $15.1 \%$ vs $9.1 \% ; \mathrm{P}<0.05$ respectively) and at discharge (7.4\% vs $4.9 \% ; \mathrm{P}<0.05$ and $12.8 \%$ vs $8.5 \% ; \mathrm{P}<0.05$ respectively).

Anemia was more present among women both ad admission and at discharge in both groups.

Sixty patient died at the hospital, 12 in the MetS group and 48 in the No-MetS with a statistically significant difference $\left(\mathrm{X}^{2}=6.6 ; \mathrm{P}<0.01\right)$. The outcome variables are reported in Table 6.

Blood pressure, weight, BMI (all inclusive criteria

Table 1. Definition of metabolic syndrome in National Cholesterol Education Program (NCEP).

\begin{tabular}{lc}
\hline Risk factor & Defining level \\
\hline $\begin{array}{l}\text { Abdominal obesity (waist circumference) } \\
\text { Men }\end{array}$ & $>102 \mathrm{~cm}(>40 \mathrm{in})$ \\
Women & $>88 \mathrm{~cm}(>35 \mathrm{in})$ \\
\hline Triglycerides & $\geq 150 \mathrm{mg} / \mathrm{dL}$ \\
\hline High-density lipoprotein cholesterol & $<40 \mathrm{mg} / \mathrm{dL}$ \\
\hline Men & $<50 \mathrm{mg} / \mathrm{dL}$ \\
\hline Bomen & $\geq 130 / \geq 85 \mathrm{mmHg}$ \\
\hline Fasting glucose & $\geq 110 \mathrm{mg} / \mathrm{dL} *$
\end{tabular}

Three out of the 5 criteria need to be met to have a positive diagnosis, which now has an International Classification of Disease (ICD) code (277.7). *The fasting glucose cut-off point has recently changed to $100 \mathrm{mg} / \mathrm{dL}$. 
in MetS) were higher in the MetS group, heart rate was faster in the MetS group, hemoglobin and creatinine were not statistically different.

\section{Discussion and Conclusions}

Metabolic syndrome is a risk factor for HF. It is independently associated with the incidence of HF in subjects with a past history of coronary heart disease. ${ }^{19}$ Moreover, according to ATP-III criteria with BMI replaced by waist circumference, it has shown to be a significant, independent predictor of subsequent HF, even after adjusting for coronary heart disease. ${ }^{8}$

The association of MetS and each of its components with the incidence of HF is well-known and it has been postulated that HF risk may not be associated with MetS per se, but rather with its individual risk factors. The strongest independent predictors of $\mathrm{HF}$ are insulin resistance or an equivalent factor (like abdominal adiposity).$^{20}$

A recent report has investigated the prevalence of
MetS in Japanese patients with $\mathrm{HF}^{21}$ and the relationship of MetS or its components with the phenotype and etiology of HF, but MetS criteria were defined as the presence of 2 or more abnormalities in addition to a waist circumference of $>85 \mathrm{~cm}$ in males and $>90 \mathrm{~cm}$ according to the new definition by the ad hoc Japanese Committee. However these criteria do not match the NCEP III criteria and are related to an Asian population, taking into account that MetS criteria are known to differ according to ethnic groups. ${ }^{22}$

The prevalence of MetS in adult Italian subjects ( $\geq 20$ years) ranges between $22 \%$ and $28 \%$, but in subjects over 50 years it ranges from $30 \%$ in males to $40 \%$ in females. In females over 60 years of age the prevalence is even higher than in males. In the Veneto region MetS may be encountered in $57 \%$ of women aged 65-84 years versus $27 \%$ of age-matched men. ${ }^{23}$ However, to our knowledge, the prevalence of MetS in HF has not yet been described in the Italian population.

Our data shows that patients with HF admitted to Italian hospitals may have MetS in nearly one third of

Table 2. Characteristics of subjects with or without metabolic syndromes.

\begin{tabular}{|c|c|c|c|c|}
\hline & $\begin{array}{c}\text { CONFINE } \\
(n=1411)\end{array}$ & $\begin{array}{c}\text { MetS } \\
(\mathrm{N}=\mathbf{5 1 5})\end{array}$ & $\begin{array}{c}\text { No-MetS } \\
(\mathrm{N}=896)\end{array}$ & $\mathbf{P}$ \\
\hline Mean age (year \pm SD) & $78.72 \pm 9.55$ & $77.8 \pm 8.5$ & $79.2 \pm 10.0$ & 0.007 \\
\hline Fasting glucose (mg/dL $\pm \mathrm{SD})$ & $136.8 \pm 70.0$ & $147.9 \pm 82.0$ & $130.5 \pm 61.2$ & 0.001 \\
\hline Waist circumference $(\mathrm{cm} \pm \mathrm{SD})$ & $94.5 \pm 15.0$ & $99.9 \pm 14.8$ & $88.0 \pm 12.5$ & 0.001 \\
\hline Smoker* & $23.6 \%$ & $23.5 \%$ & $23.7 \%$ & 0.05 \\
\hline $\mathrm{BMI}^{\circ}$ & $27.1 \pm 5.3$ & $28.3 \pm 5.4$ & $26.2 \pm 5.1$ & 0.001 \\
\hline Cholesterol (mg/dL $\pm \mathrm{SD})$ & $153.1 \pm 52.6$ & $156.1 \pm 56.4$ & $150.8 \pm 49.6$ & 0.0064 \\
\hline $\mathrm{HDL}$ cholesterol $(\mathrm{mg} / \mathrm{dL} \pm \mathrm{SD})^{\#}$ & $43.3 \pm 21.4$ & $38.0 \pm 13.9$ & $48.7 \pm 25.7$ & 0.001 \\
\hline Triglycerides $(\mathrm{mg} / \mathrm{dL} \pm \mathrm{SD})$ & $96.6 \pm 48.3$ & $113.0 \pm 59.0$ & $84.3 \pm 33.5$ & 0.001 \\
\hline NYHA on admission & $3.15 \pm 0.76$ & $3.14 \pm 0.74$ & $3.16 \pm 0.77$ & 0.64 \\
\hline NYHA at discharge & $2.25 \pm 0.74$ & $2.17 \pm 0.74$ & $2.30 \pm 0.75$ & 0.038 \\
\hline NYHA III, IV on admission (\%) & $81.7 \%$ & $81.6 \%$ & $81.7 \%$ & 0.9 \\
\hline NYHA III, IV at discharge (\%) & $30.4 \%$ & $27.4 \%$ & $32.1 \%$ & 0.1 \\
\hline $\operatorname{LVEF}(\%)^{\wedge}$ & $43.1 \pm 12.3$ & $43.9 \pm 11.9$ & $42.4 \pm 12.6$ & 0.2 \\
\hline$\%$ of LVEF $>$ or $=50 \%$ on admission & $33.8 \%$ & $34.6 \%$ & $33.2 \%$ & 0.8 \\
\hline$\%$ of $\mathrm{LVEF}>$ or $=30 \%$ on admission & $18.3 \%$ & $14.7 \%$ & $21.7 \%$ & 0.2 \\
\hline \multicolumn{5}{|l|}{ Vital signs } \\
\hline SBP & $140.8 \pm 26.8$ & $151.3 \pm 24.1$ & $134.9 \pm 26.5$ & 0.001 \\
\hline DBP & $81.3 \pm 13.1$ & $85.9 \pm 12.3$ & $78.6 \pm 13.7$ & 0.001 \\
\hline Heart rate (beat/min) & $91.4 \pm 21.6$ & $93.8 \pm 21.5$ & $90.0 \pm 21.6$ & 0.001 \\
\hline
\end{tabular}

CONFINE, Comorbidities and Outcome iN patients with chronic heart Failure: a study in INternal mEdicine units; MetS, metabolic syndrome; No-MetS, without metabolic syndrome; SD, standard deviation; BMI, body mass index; HDL, high-density lipoprotein; NYHA, New York Heart Association; LVEF, left ventricular ejection fraction; SBP, systolic blood pressure; DBP, diastolic blood pressure. ${ }^{n} n=313$ smokers, 99 former smoker (quitted from more than 6 months) $n=1330$ NYHA class registered on admission (MetS=487, No-MetS $=843$ ); ${ }^{\circ} \mathrm{n}=590$ data sheets; ${ }^{n} \mathrm{n}=728$ data sheets; ${ }^{\circledR} \mathrm{n}=1174$ NYHA class registered at discharge $(\mathrm{MetS}=437$, NoMetS=737); $\wedge^{n}=827$ echocardiogram performed. 
the whole population. The subjects with MetS have a quite different phenotype. In fact they are younger than their No-MetS counterparts and, as expected, females are older than males with a mean difference of two years. Apart from inclusion criteria, which obviously demonstrate a remarkable statistically significant difference from other patients with HF, these patients show also a faster heart rate $(93.8+21.9 v s 90.0 v s+21.3)$, taking into account that the heart rate is a well-known independent risk factor for $\mathrm{HF}$ and its outcome. ${ }^{24}$

Table 3. Clinical and laboratory characteristics in subjects with or without metabolic syndromes (number of patients in brackets).

\begin{tabular}{|c|c|c|c|c|c|c|}
\hline & \multicolumn{2}{|c|}{ Male } & \multicolumn{4}{|c|}{ Female } \\
\hline & $\begin{array}{c}\text { MetS } \\
(\mathbf{N}=\mathbf{2 3 1})\end{array}$ & $\begin{array}{c}\text { No-MetS } \\
(\mathrm{N}=\mathbf{3 3 0})\end{array}$ & $\mathbf{P}$ & $\begin{array}{c}\text { MetS } \\
(\mathrm{N}=\mathbf{2 8 4})\end{array}$ & $\begin{array}{c}\text { No-MetS } \\
(\mathrm{N}=\mathbf{4 0 7})\end{array}$ & $\mathbf{P}$ \\
\hline Mean age (year \pm SD) & $75.1 \pm 8.8$ & $77.4 \pm 10.5$ & 0.0046 & $79.9 \pm 7.6$ & $81.2 \pm 9.2$ & 0.008 \\
\hline Fasting blood glucose on admission & $139.9 \pm 69.8$ & $129.11 \pm 60.3$ & 0.001 & $154.3 \pm 90.1$ & $132.0 \pm 64.5$ & 0.001 \\
\hline Cholesterol (mg/dL $\pm \mathrm{SD})$ & $152.4 \pm 47.9$ & $147.5 \pm 46.0$ & 0.197 & $159.0 \pm 62.4$ & $154.4 \pm 53.7$ & 0.22 \\
\hline Cholesterol HDL (mg/dL \pm SD) (747) & $34.9 \pm 11.9$ & $46.1 \pm 21.4$ & 0.001 & $40.1 \pm 14.9$ & $52.3 \pm 30.6$ & 0.001 \\
\hline Triglycerides on admission $(\mathrm{mg} / \mathrm{dL} \pm \mathrm{SD})(947)$ & $115.7 \pm 52.9$ & $86.1 \pm 35.1$ & 0.001 & $110.4 \pm 63.6$ & $82.1 \pm 31.7$ & 0.001 \\
\hline Waist circumference cm (598) & $104.68 \pm 13.7$ & $91.0 \pm 11.2$ & 0.001 & $96.2 \pm 14.5$ & $84.0 \pm 13.13$ & 0.001 \\
\hline BMI (1108) & $28.5 \pm 5.2$ & $26.2 \pm 4.6$ & 0.001 & $28.12 \pm 4.6$ & $26.1 \pm 5.6$ & 0.001 \\
\hline NYHA on admission (1330) & $3.1 \pm 0.7$ & $3.1 \pm 0.8$ & 0.87 & $3.1 \pm 0.8$ & $3.2 \pm 0.7$ & 0.32 \\
\hline NYHA at discharge (1174) & $2.1 \pm 0.8$ & $2.3 \pm 0.8$ & 0.019 & $2.2 \pm 0.7$ & $2.3 \pm 0.7$ & 0.047 \\
\hline NYHA III-IV(\%) on admission & $83.5 \%$ & $80.6 \%$ & 0.02 & $80.1 \%$ & $84.3 \%$ & 0.07 \\
\hline SBP & $151.6 \pm 24.9$ & $134.5 \pm 23.2$ & 0.001 & $150.8 \pm 23.5$ & $135.6 \pm 25.9$ & 0.001 \\
\hline $\mathrm{DBP}$ & $86.5 \pm 12.62$ & $78.73 \pm 13.5$ & 0.001 & $85.3 \pm 12.1$ & $78.7 \pm 12.9$ & 0.001 \\
\hline Heart rate (beat $/ \mathrm{min}$ ) & $93.7 \pm 21.5$ & $89.6 \pm 21.4$ & 0.022 & $93.96 \pm 22.0$ & $90.3 \pm 21.3$ & 0.028 \\
\hline LVEF (\%) & $42.5 \pm 10.8$ & $41.8 \pm 12.3$ & 0.4 & $45.15 \pm 12.9$ & $43.6 \pm 12.7$ & 0.14 \\
\hline$\%$ LVEF $>=50 \%$ on admission $*$ & $38.6 \%$ & $49.5 \%$ & 0.28 & $61.4 \%$ & $50.5 \%$ & 0.9 \\
\hline
\end{tabular}

MetS, metabolic syndrome; No-MetS, without metabolic syndrome; SD, standard deviation; HDL, high-density lipoprotein; BMI, body mass index; NYHA, New York Heart Association; SBP, systolic blood pressure; DBP, diastolic blood pressure; LVEF, left ventricular ejection fraction. *Number of LVEF $>$ or $=50 \%$ was 203 of 827 echocardiography performed.

Table 4. Therapy in subjects with or without metabolic syndromes.

\begin{tabular}{|c|c|c|c|c|}
\hline & $\begin{array}{c}\text { Total\% } \\
(\mathrm{N}=1411)\end{array}$ & $\begin{array}{l}\text { MetS\% } \\
\text { (N=507) }\end{array}$ & $\begin{array}{c}\text { No-MetS\% } \\
(\mathrm{N}=894)\end{array}$ & $\mathbf{P}\left(\chi^{2}\right)^{*}$ \\
\hline Allopurinol & 16.0 & 15.3 & 16.3 & 0.64 \\
\hline ARBs alone & 14.6 & 18.9 & 12.2 & 0.001 \\
\hline ACEI & 51.9 & 53.4 & 51.0 & 0.37 \\
\hline $\mathrm{ACEI}+\mathrm{ARBS}^{\circ}$ & 66.5 & 72.3 & 63.3 & 0.01 \\
\hline Acetylsalicylic acid & 34.2 & 36.6 & 32.7 & 0.13 \\
\hline$\beta$ blockers & 23.8 & 28.9 & 22.0 & 0.001 \\
\hline Ca-channel blockers & 13.9 & 16.2 & 12.6 & 0.06 \\
\hline Digitalis & 30.4 & 32.2 & 29.3 & 0.77 \\
\hline Diuretics (oral) & 46.5 & 43.2 & 51.6 & 0.06 \\
\hline Spironolactone & 20.9 & 20.1 & 21.3 & 0.58 \\
\hline Warfarin & 23.0 & 23.8 & 22.4 & 0.70 \\
\hline
\end{tabular}


On admission NYHA class III-IV and marked depressed or preserved systolic function are similar. Taking into account that these baseline values on admission for HF may be considered the same in the two groups, how can we justify the lower hospital mortality of the MetS subjects? These patients are more hypertensive, have higher blood glucose levels on admission, have a faster heart rate, which are all well-known significant risk factors ${ }^{25}$ for adverse cardiovascular events, yet they die less than their counterparts. Actually our data shows that MetS patients with HF have a younger age; also considering that the difference of mean age is about two years in both sexes. Since HF has an age-dependent prognosis, ${ }^{26}$ this outcome obviously mirrors this variable.

It is well-known that each component of the MetS and MetS itself is positively correlated to cognitive defects. ${ }^{27-30}$ In our study dementia is less represented in the MetS subjects. It has been recently reported that MetS measured in late life is not associated with a risk of dementia and after age 75 MetS patients may even have lower risk of dementia. ${ }^{31,32}$ In other words, cognitive defects are age-related, but in MetS patients their prevalence seems to be less evident. Therefore considering that dementia is a risk factor for a negative HF outcome (as we have previously shown in the whole population of the CONFINE study), but it is less prevalent in MetS subjects, we may justify the better outcome of the patients in our study.

This may also be due to a more extensive use of ARBs and $\beta$ blockers (and marginally of diuretics and $\mathrm{Ca}$ channel blockers) in the MetS group, taking into account that these drugs are used to treat hypertension, which is one of the components of MetS. More specifically $\beta$ blockers, the cornerstone of heart failure treatment, are more used on admission in the MetS subjects than in No-MetS group. In our opinion higher blood pressure in MetS subjects, reducing the chance of hypotension, makes it much easier and safer to prescribe $\beta$ blockers.

Table 5. Comorbidities in subjects with or without metabolic syndromes.

\begin{tabular}{|c|c|c|c|c|c|c|}
\hline & \multicolumn{2}{|c|}{ MetS } & \multirow{2}{*}{$\mathbf{P}$} & \multicolumn{2}{|c|}{ No-MetS } & \multirow[b]{2}{*}{$\mathbf{P}$} \\
\hline & $\begin{array}{c}\text { Admission } \\
(\mathrm{N}=514)\end{array}$ & $\begin{array}{c}\text { Discharge } \\
(\mathrm{N}=\mathbf{4 6 3})\end{array}$ & & $\begin{array}{c}\text { Admission } \\
(\mathrm{N}=922)\end{array}$ & $\begin{array}{c}\text { Discharge } \\
(\mathbf{N}=823)\end{array}$ & \\
\hline GFR* & & $x+3$ & & & & \\
\hline Normal & 56.8 & 57.4 & $\mathrm{~ns}$ & 55.2 & 58 & ns \\
\hline $61-89$ & 16.7 & 19.2 & ns & 14.4 & 14.7 & ns \\
\hline $31-60$ & 19.4 & 17.5 & ns & 18 & 16.1 & $\mathrm{~ns}$ \\
\hline $0-30$ & 6.4 & 5.4 & ns & 12 & 10.5 & ns \\
\hline Dialysis & 0.1 & 0.1 & ns & 0.3 & 0.5 & ns \\
\hline Diabetes & 39.2 & 37.3 & ns & 28.7 & 27 & ns \\
\hline \multicolumn{7}{|l|}{ Hypertension $^{\circ}$} \\
\hline No & 20.6 & 37.3 & 0.001 & 52.1 & 60.8 & 0.001 \\
\hline Mild & 40.6 & 51.6 & 0.001 & 31 & 30.5 & ns \\
\hline Moderate & 31.5 & 10.8 & 0.001 & 18.1 & 8.2 & 0.001 \\
\hline Severe & 7.2 & 0.1 & 0.001 & 4.4 & 0.3 & 0.001 \\
\hline COPD & 25.1 & 25.2 & ns & 27.6 & 26.9 & ns \\
\hline \multicolumn{7}{|l|}{ Dementia } \\
\hline No & 82.1 & 82.5 & 0.9 & 76.4 & 76.6 & 0.9 \\
\hline Mild (3-4) & 10.9 & 10.6 & 0.9 & 12.1 & 13.4 & 0.5 \\
\hline Moderate (5-6) & 4.6 & 4.7 & 0.9 & 7.3 & 6.7 & 0.6 \\
\hline Severe $>$ or $=7$ & 2.3 & 2.1 & 0.9 & 4.1 & 3.4 & 0.01 \\
\hline Chronic disease $^{\#}$ & 7.2 & 7.1 & 0.9 & 7.6 & 7.5 & 0.9 \\
\hline Cachexia $^{\S}$ & 4.8 & 4.3 & ns & 7.8 & 7.3 & ns \\
\hline Anemia $^{\wedge}$ & 40.4 & 36.9 & 0.01 & 40.5 & 37.2 & 0.01 \\
\hline
\end{tabular}

MetS, metabolic syndrome; No-MetS, without metabolic syndrome; GFR, glomerular filtration rate; ns, not significant; COPD, chronic obstructive pulmonary disease. ${ }^{*}$ GFR according to the Cockroft Gould formula; ${ }^{\circ}$ ESH-ESC criteria: mild=140/85-159/99; moderate $=160 / 100-179 / 109 ;$ severe $>$ or $=180 / 100 ;{ }^{*}$ Include rheumatoid arthritis, systemic lupus erythematosus, Crohn's disease, ulcerative colitis and chronic hepatitis or cirrhosis; ${ }^{\circledR} \mathrm{BMI}<18.5 ;{ }^{\wedge}$ according WHO criteria. 
Table 6. Outcome variables in subjects with or without metabolic syndromes.

\begin{tabular}{|c|c|c|c|c|c|c|}
\hline & \multicolumn{2}{|c|}{ Deceased $(\mathrm{N}=60)$} & \multirow[b]{2}{*}{$\mathbf{P}$} & \multicolumn{2}{|c|}{ Not deceased $(\mathrm{N}=1351)$} & \multirow[b]{2}{*}{$\mathbf{P}$} \\
\hline & $\begin{array}{c}\text { MetS } \\
(\mathrm{N}=12)\end{array}$ & $\begin{array}{c}\text { No-MetS } \\
(\mathrm{N}=48)\end{array}$ & & $\begin{array}{c}\text { MetS } \\
(\mathrm{N}=503)\end{array}$ & $\begin{array}{c}\text { No-MetS } \\
\text { (N=848) }\end{array}$ & \\
\hline NYHA class on admission & $4.00 \pm 00$ & $3.39 \pm 0.64$ & 0.005 & $3.11 \pm 0.74$ & $3.15 \pm 0.71$ & 0.3 \\
\hline Weight & $88.2 \pm 29.7$ & $72.55 \pm 18.4$ & 0.05 & $78.2 \pm 18.5$ & $74.5 \pm 18.4$ & 0.005 \\
\hline BMI* & $27.1 \pm 5.3$ & $24.2 \pm 5.3$ & 0.16 & $28.3 \pm 5.4$ & $26.2 \pm 5.8$ & 0.001 \\
\hline $\mathrm{LVEF}^{\circ}$ & $31.8 \pm 7.5$ & $35.5 \pm 16.5$ & 0.4 & $44.3 \pm 11.8$ & $42.6 \pm 12.5$ & 0.17 \\
\hline LVEF $>50 \%$ & 0 & 0 & 0 & $35.6 \%$ & $33.4 \%$ & \\
\hline $\mathrm{LVEF}<30 \%$ & $50 \%$ & $50 \%$ & 0 & $13.5 \%$ & $20.1 \%$ & \\
\hline SBP & $141.7 \pm 15.6$ & $124.7 \pm 30.7$ & 0.07 & $151.5 \pm 24.2$ & $135.4 \pm 24.1$ & 0.001 \\
\hline DBP & $83.7 \pm 8.8$ & $71.3 \pm 13.4$ & 0.005 & $85.9 \pm 12.4$ & $79.0 \pm 13.0$ & 0.001 \\
\hline Heart rate & $101.0 \pm 28.5$ & $93.3 \pm 27.5$ & 0.4 & $93.6 \pm 21.7$ & $89.8 \pm 21.0$ & 0.001 \\
\hline Hemoglobin (g/dL) & $11.4 \pm 2.3$ & $11.4 \pm 2.5$ & 0.08 & $12.0 \pm 2.9$ & $12.2 \pm 3.1$ & 0.5 \\
\hline Creatinine $(\mathrm{mg} / \mathrm{mL})$ & $1.49 \pm 0.74$ & $1.96 \pm 1.01$ & 0.11 & $1.48 \pm 1.00$ & $1.47 \pm 0.92$ & 0.8 \\
\hline
\end{tabular}

MetS, metabolic syndrome; No-MetS, without metabolic syndrome; NYHA, New York Heart Association; BMI, body mass index; LVEF, left ventricular ejection fraction; SBP, systolic blood pressure; DBP, diastolic blood pressure. $* 1107$ data sheets; ${ }^{\circ} \mathrm{N}=405$ echocardiography on admission.

Consequently hypertension, a significant risk factor for HF, may be paradoxically and indirectly a protective risk factor for $\mathrm{HF}$ in MetS patients: i) because they must be treated with drugs which lower blood pressure; ii) because among these drugs, the most widely used are $\beta$ blockers and ARBs that are the cornerstone of HF treatment; and iii) because hypertension makes the prescription of these agents safer.

We have not taken into account the effects of the lipid lowering therapy (statins) that is now considered useful in countering risk factors for $\mathrm{HF}^{33}$ since we had not enough data to perform a statistical analysis.

Therefore taking into account that the NYHA class is a continuous variable and that the value of NYHA class on admission in both groups is the same: i) if the mean NYHA class at discharge was better in MetS subjects compared with No-MetsS (do they respond better to treatment?); and ii) if the mean LVEF value on admission in MetS subjects deceased was lower than in their counterparts, then may we argue that a negative prognosis in MetS subjects is associated with a more impaired cardiovascular function?

In other words may the paradox of obesity and MetS ${ }^{34-37}$ be confirmed?

From our data we may suggest that the interaction between MetS and obesity reflects a sort of doublefaced Janus phenomenon. They are well-recognized risk factors for $\mathrm{HF}^{38}$ in young people, but the older the age, the more they lose their dangerous potential so much so that in elderly patients with HF they even become predictive of a positive outcome.

\section{References}

1. Grundy SM, Cleeman JI, Daniels SR, et al. Diagnosis and management of the metabolic syndrome: an American Heart Association/National Heart, Lung, and Blood Institute Scientific Statement. Circulation 2005;112: 2735-52.

2. Wilson PW, Kannel WB, Silbershatz H, D'Agostino RB. Clustering of metabolic factors and coronary heart disease. Arch Intern Med 1999;159:1104-9.

3. Kasai T, Miyauchi K, Kubota N, et al. The relationship between the metabolic syndrome defined by various criteria and the extent of coronary artery disease. Atherosclerosis 2008;197:944-50.

4. McNeill AM, Katz R, Girman CJ, et al. Metabolic syndrome and cardiovascular disease in older people: the cardiovascular health study. J Am Geriatr Soc 2006;54:1317.

5. Wang J, Sarnola K, Ruotsalainen S, et al. The metabolic syndrome predicts incident congestive heart failure: a 20 -year follow-up study of elderly Finns. Atherosclerosis 2010;210:237-42.

6. Bahrami H, Bluemke DA, Kronmal R, et al. Novel metabolic risk factors for incident heart failure and their relationship with obesity: The MESA (Multi-Ethnic Study of Atherosclerosis) study. J Am Coll Cardiol 2008;51:1775-83.

7. Ingelsson E, Sundström J, Ärnlöv J, et al. Insulin resistance and risk of congestive heart failure. JAMA 2005;294:334-40.

8. Ingelsson E, Arnlov J, Lind L, Sundstrom J. Metabolic syndrome and risk for heart failure in middle-aged men. Heart 2006;92:1409-13.

9. Badano LP, Di Lenarda A, Belotti P, et al. Patients with chronic heart failure encountered in daily clinical practice are different from the "typical" patient enrolled in therapeutic trials. Ital Heart J 2003;4:84-91. 
10. Gheorghiade M, Filippatos. Reassessing treatment of acute heart failure syndromes: the ADHERE registry. Eur Heart J Suppl 2005;7:B13-9.

11. Konstam MA. Progress in heart failure management?: Lessons from the real world. Circulation 2000;102:1076-8.

12. Biagi P, Gussoni G, Iori I, et al. Clinical profile and predictors of in-hospital outcome in patients with heart failure: the FADOI "CONFINE" Study. Int J Cardiol 2011;6;152:88-94.

13. Swedberg K, Cleland J, Dargie H, et al. Guidelines for the diagnosis and treatment of chronic heart failure - executive summary (update 2005): the Task Force for the Diagnosis and Treatment of Chronic Heart Failure of the European Society of Cardiology. Eur Heart J 2005; 26:1115-40.

14. National Cholesterol Education Program (NCEP) Expert Panel on Detection, Evaluation, and Treatment of High Blood Cholesterol in Adults (Adult Treatment Panel III). Third Report of the National Cholesterol Education Program (NCEP) Expert Panel on Detection, Evaluation, and Treatment of High Blood Cholesterol in Adults (Adult Treatment Panel III) final report. Circulation 2002;106:3143-421.

15. Mancia G, de Backer G, Dominiczak A, et al. Guidelines for the management of arterial hypertension. The Task Force for the Management of Arterial Hypertension of the European Society of Hypertension (ESH) and of the European Society of Cardiology (ESC). J Hypertens 2007;25:1105-87.

16. [No authors listed]. Nutritional anaemias. Report of a WHO scientific group. World Health Organ Tech Rep Ser 1968;405:1-40.

17. Pfeiffer E. A short portable mental status questionnaire for the assessment of organic brain deficit in elderly patients. J Am Geriatr Soc 1975;23:433-4.

18. Mahoney FI, Barthel DW. Functional evaluation: the Barthel index. Md State Med J 1965;14:61-5.

19. Butler J, Rodondi N, Zhu Y, et al. Metabolic syndrome and the risk of cardiovascular disease in older adults. J Am Coll Cardiol 2006;47:1595-602.

20. Li C, Ford ES, McGuire LC, Mokdad AH. Association of metabolic syndrome and insulin resistance with congestive heart failure: Findings from the Third National Health and Nutrition Examination Survey. J Epidemiol Commun Health 2007;61:67-73.

21. Miura Y, Fukumoto Y, Shiba N, et al. Prevalence and clinical implication of metabolic syndrome in chronic heart failure: report from MetS-CHF Study. Circ J 2010;74:2612-21.

22. Wulan SN, Westerterp KR, Plasqui G. Ethnic differences in body composition and the associated metabolic profile: a comparative study between Asians and Caucasians Maturitas 2010;65:315-9.

23. Manzato E, Romanato G, Zambon S, et al. Metabolic syndrome and cardiovascular disease in the elderly: the Progetto Veneto Anziani (Pro.V.A.) Study. Aging Clin Exp Res 2008;20:47-52.

24. Böhm M, Swedberg K, Komajda M, et al. Heart rate as a risk factor in chronic heart failure (SHIFT): the association between heart rate and outcomes in a randomised placebo-controlled trial. Lancet 2010;376:886-94.

25. Hjalmarson A. Heart rate: an independent risk factor in cardiovascular disease. Eur Heart J Suppl 2007;9:F3-7.

26. Mosterd A, Cost B, Hoes AW, et al. The prognosis of heart failure in the general population: The Rotterdam Study. Eur Heart J 2001;22:1318-27.

27. Xu W, Qiu C, Winblad B, Fratiglioni L. The effect of borderline diabetes on the risk of dementia and Alzheimer's disease. Diabetes 2007;56:211-6.

28. Xu W, Qiu C, Gatz M, et al. Mid- and late-life diabetes in relation to the risk of dementia a population-based twin study. Diabetes 2009;58:71-7.

29. Luchsinger JA, Small S, Biessels G. Should we target insulin resistance to prevent dementia due to Alzheimer disease? Arch Neurol 2011;68:17-8.

30. Raffaitin C, Gin H, Empana JP, et al. Metabolic syndrome and risk for incident Alzheimer's disease or vascular dementia. The Three-City Study. Diabetes Care 2009;32:169-74.

31. Forti P, Pisacane N, Rietti E, et al. Metabolic syndrome and risk of dementia in older adults. J Am Geriatr Soc 2010;58:487-92.

32. Muller M, Tang M, Schupf N, et al. Metabolic syndrome and dementia risk in a multiethnic elderly cohort. Dement Geriatr Cogn Disord 2007;24:185-92.

33. Davis BR, Kostis JB, Simpson LM. Heart failure with preserved and reduced left ventricular ejection fraction in the antihypertensive and lipid-lowering treatment to prevent heart attack trial. Circulation 2008;118:2259-67.

34. Kalantar-Zadeh K, Block G, Horwich T, Fonarow GC. Reverse epidemiology of conventional cardiovascular risk factors in patients with chronic heart failure. J Am Coll Cardiol 2004;43:1439-44.

35. Fonarow GC, Srikanthan P, Costanzo MR, et al. An obesity paradox in acute heart failure: analysis of body mass index and inhospital mortality for 108,927 patients in the Acute Decompensated Heart Failure National Registry. Am Heart J 2007;153:74-81.

36. Gaddam KK, Ventura HO, Lavie CJ. Metabolic syndrome and heart failure - the risk, paradox, and treatment. Curr Hypertens Rep 2011;13:142-8.

37. Kenchaiah S, Pocock SJ, Wang D, et al. Body mass index and prognosis in patients with chronic heart failure: Insights from the Candesartan in Heart failure: assessment of Reduction in Mortality and morbidity (CHARM) Program. Circulation 2007;116:627-36.

38. Kenchaiah S, Evans JC, Levy D, et al. Obesity and the risk of heart failure. N Engl J Med 2002;347:305-13. 